\title{
Discovery of Oxazol-2-amine Derivatives as Potent Novel FLT3 Inhibitors
}

\author{
Hyo Jeong Kim ${ }^{1}$, Hwani Ryu ${ }^{1,2}{ }^{\text {, Jie-Young Song }}{ }^{1}{ }^{\circledR}$, Sang-Gu Hwang ${ }^{1}$, Shivakumar S. Jalde ${ }^{3} \mathbb{D}^{\text {, }}$ \\ Hyun-Kyung Choi ${ }^{3, *}$ and Jiyeon Ahn ${ }^{1, *}$ (I) \\ 1 Division of Radiation Biomedical Research, Korea Institute of Radiological \& Medical Sciences, Seoul 01812, \\ Korea; hjkim@kirams.re.kr (H.J.K.); hwanya85@kirams.re.kr (H.R.); immu@kirams.re.kr (J.-Y.S.); \\ sgh63@kirams.re.kr (S.-G.H.) \\ 2 Department of Biology, Korea University, Seoul 02841, Korea \\ 3 Department of Medicinal Chemistry, Jungwon University, Goesan 28024, Korea; \\ jaldeshivkumar641@gmail.com \\ * $\quad$ Correspondence: hkchoi45@daum.net (H.-K.C.); ahnjy@kirams.re.kr (J.A.); Tel.: +82-2-970-1311 (J.A.)
}

Received: 15 September 2020; Accepted: 4 November 2020; Published: 5 November 2020

\begin{abstract}
Internal tandem duplication (ITD) of FMS-like tyrosine kinase 3 (FLT3) is the most common mutation in patients with acute myeloid leukemia (AML). FLT3-ITD ${ }^{+}$induces constitutive activation of FLT3, causing an abnormally rapid proliferation of cancer cells. In this study, we identified novel FLT3 inhibitors and investigated 5-(4-fluorophenyl)- $N$-phenyloxazol-2-amine (compound 7; 7c) as candidates for the treatment of AML. The results showed that $7 \mathrm{c}$ inhibited the activities of FLT3 and mutated FLT3 in a cell-free kinase assay and Molm-13 and MV4-11 cells, as well as the proliferation of FLT3-ITD ${ }^{+}$AML cells, increasing apoptosis. The anti-leukemic activity of $\mathbf{7 c}$ was confirmed by in vivo tumor growth inhibition in MV4-11 xenograft mice. Besides, $7 \mathrm{c}$ suppressed the expression of DNA damage repair genes. Combination treatment with $7 \mathrm{c}$ and olaparib (a poly (ADP-ribose) polymerase [PARP] inhibitor) synergistically inhibited cell proliferation in Molm-13 and MV4-11 cells. Our findings demonstrated that $7 \mathrm{c}$ is a therapeutic candidate targeting FLT3 for AML treatment and suggested that combination treatment with $7 \mathrm{c}$ and a PARP inhibitor may be an effective therapy regimen for FLT3-mutated AML.
\end{abstract}

Keywords: FLT3 inhibitor; acute myeloid leukemia; DNA damage repair; combination therapy; PARP1 inhibitor

\section{Introduction}

Acute myeloid leukemia (AML) is a heterogeneous malignancy characterized by rapid clonal proliferation or poor differentiation of myeloid lineage cells in the hematopoietic system. The incidence of AML increases with age and occurs mainly in adults, accounting for nearly $80 \%$ of AML cases [1]. The standard therapeutic protocol for AML is combination treatment with cytarabine for 7-10 days and daunorubicin for 3 days (" $7+3$ " regimen) with or without hematopoietic stem cell transplantation (HSCT) [2-4]. However, the " $7+3$ " regimen is mostly beneficial for patients younger than 60 years who show a 5 -year overall survival (OS) of $40 \%$, but not for patients older than 60 years (OS, 5-15\%), mainly due to underlying health conditions [5].

Genomic studies on AML have identified several recurrently mutated genes that enable its classification and diagnosis using predictive biomarkers to help develop anti-leukemic agents. One of the most frequently mutated genes in AML is the FMS-like tyrosine kinase 3 receptor gene (FLT3), a well-characterized oncogenic mutation; it occurs in approximately $30 \%$ of patients. Approximately $25 \%$ of patients with AML have an internal tandem duplication (ITD), whereas $5-10 \%$ of patients with 
AML have point mutations in the tyrosine kinase domain (TKD), typically at codon D835 [6,7]. FLT3 is a member of class III receptor tyrosine kinase family that is activated by binding to FLT3 ligands, and it induces the proliferation and differentiation of hematopoietic precursor cells. However, FLT3-ITD and FLT3-TKD can constitutively activate FLT3 and induce rapid cell proliferation via the activation of its downstream signaling molecules, including the signal transducer and activator of transcription 5 (STAT5).

After decades of standard treatments, the U.S. Food and Drug Administration (FDA) approved FLT3-targeting therapeutic agents, allowing targeted therapy for FLT3-mutated AML. First-generation FLT3 inhibitors, such as sunitinib, midostaurin, lestaurtinib, sorafenib, ponatinib, and tandutinib, are multi-kinase inhibitors approved by the FDA in 2017 for the treatment of FLT3-mutated AML. Inhibition of multiple RTKs induces AML cell death via the inhibition of FLT3; however, these inhibitors are cytotoxic to healthy cells owing to unclear target specificity. Second-generation FLT3 inhibitors, such as KW-2449, crenolanib, gilteritinib, and quizartinib, which mainly target FLT3 mutants, have relatively low toxicity [8]. Of these, quizartinib is a more potent and selective FLT3 inhibitor than midostaruin, but the FDA declined it in 2019. Thus, there is a need to develop novel inhibitors targeting FLT3.

Previous studies suggest that FLT3-ITD ${ }^{+}$AML cells generate high levels of reactive oxygen species (ROS) that induce DNA damage, mutations, double-strand DNA breaks (DSB), and chromosomal instability, but they can survive owing to enhanced DNA repair activities [9-12]. Interestingly, FLT3 inhibitors downregulate DNA repair genes of the homologous recombination (HR) and nonhomologous end-joining (NHEJ) repair pathways. PARP1 is an abundant nuclear protein that acts as an early DNA damage sensor to rapidly recruit DNA repair enzymes to single-strand DNA break or DSB sites by adding ADP-ribose polymers to lysine residues and target proteins, a process known as poly(ADP-ribosyl)ation (PARylation) $[13,14]$. Therefore, an FLT3 inhibitor-mediated "BRCAness/DNA-PKness" phenotype can induce synthetic lethality with a PARP inhibitor in combination therapy.

In this study, to identify tyrosine kinase inhibitors targeting FLT3, we designed and synthesized 11 oxazol-2-amine-based small-molecule compounds. We aimed to investigate the anti-leukemic effect of the novel compounds and the combination therapeutic effect of the novel FLT3 compound with a PARP1 inhibitor in FLT3-ITD ${ }^{+}$AML cells. Our study will provide additional data for the use of FLT3 inhibitors in AML treatment protocols.

\section{Results}

\subsection{7c Has Anti-Leukemic Activity in AML Cells Both In Vitro and In Vivo}

Of the eleven synthesized compounds (Scheme 1 and Table 1), 10c, 11c, 5c, 2c, 1c, 6c, and 4c showed the highest FLT3 inhibitory activity at $100 \mathrm{nM}$. Of the eight compounds that showed the inhibitory kinase activity against FLT3-ITD and FLT3-D835Y in vitro, five compounds (7c, 5c, 4c, 2c, and $6 \mathrm{c}$ ) inhibited the growth of Molm-13 and MV4-11 cells at $100 \mathrm{nM}$, but not that of AML HL-60 (FLT3-null) cells at 10,000 nM (Table 1) and human chronic myeloid leukemia K562 cells (FLT3 WT) at 1000 nM (Figure S1). Overall, 7c (5-(4-fluorophenyl)-N-phenyloxazol-2-amine) was the most effective in inhibiting the growth of Molm-13 and MV4-11 cells and was further examined as a novel putative FLT3 inhibitor (Figure 1a, Table 2, and Figure S2). 


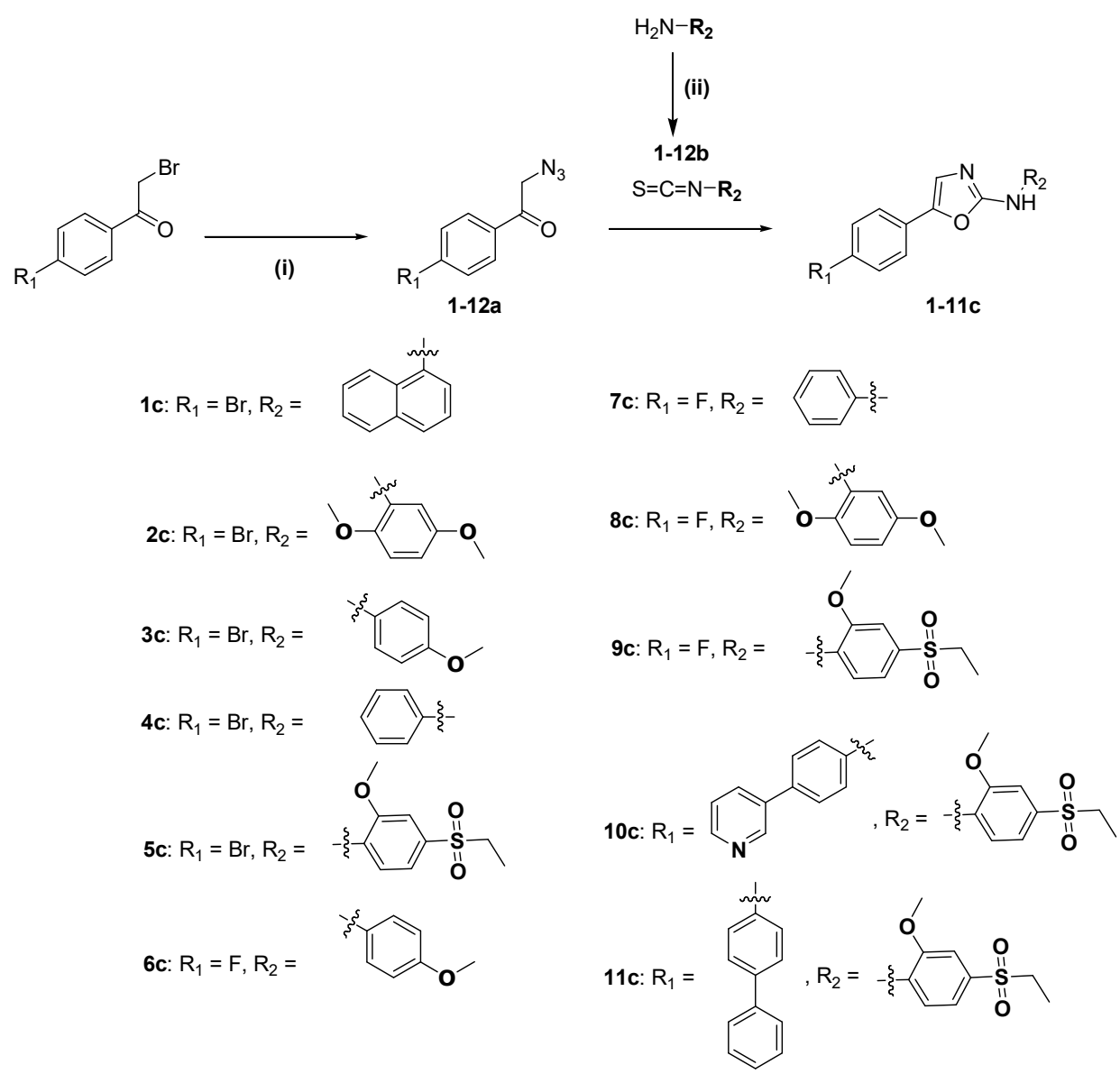

Scheme 1. Reagents and conditions: (i) sodium azide, acetone, $\mathrm{H}_{2} \mathrm{O}$ room temperature for $16 \mathrm{~h}$; (ii) thiophosgene, dichloromethane for $4 \mathrm{~h}$; and (iii) $\mathrm{PPh}_{3}$, dioxane $90{ }^{\circ} \mathrm{C}$ for $4 \mathrm{~h}$.

Table 1. Inhibitory activities of 11 synthesized compounds ( $100 \mathrm{nM}$ concentration) on FMS-like tyrosine 3 (FLT3) kinases and cell growth.

\begin{tabular}{|c|c|c|c|c|c|c|c|c|}
\hline \multirow{2}{*}{$\begin{array}{c}\text { Compound } \\
\text { Identity }\end{array}$} & \multicolumn{2}{|c|}{ Structure } & \multicolumn{3}{|c|}{ In Vitro Kinase Inhibition (\%) } & \multicolumn{3}{|c|}{ Cell Growth Inhibition (\%) } \\
\hline & $\mathbf{R} 1$ & R2 & FLT3 & $\begin{array}{c}\text { FLT3 } \\
\text { (D835Y) }\end{array}$ & $\begin{array}{l}\text { FLT3 } \\
\text { (ITD) }\end{array}$ & MV4-11 & Molm-13 & HL-60 \\
\hline 1c & $\mathrm{Br}$ & & $23 \pm 4$ & $47 \pm 1$ & $63 \pm 1$ & 0 & 0 & 0 \\
\hline $2 c$ & $\mathrm{Br}$ & & $64 \pm 9$ & $74 \pm 0$ & $82 \pm 2$ & $24 \pm 5$ & $34 \pm 3$ & 0 \\
\hline $3 c$ & $\mathrm{Br}$ & & 0 & 0 & $15 \pm 2$ & 0 & 0 & 0 \\
\hline $4 c$ & $\mathrm{Br}$ & & $28 \pm 2$ & $15 \pm 4$ & $57 \pm 1$ & $26 \pm 2$ & 0 & 0 \\
\hline $5 c$ & $\mathrm{Br}$ & & $87 \pm 0$ & $92 \pm 1$ & $89 \pm 1$ & $38 \pm 4$ & $11 \pm 4$ & 0 \\
\hline $6 c$ & $\mathrm{~F}$ & & $41 \pm 6$ & $27 \pm 3$ & $66 \pm 1$ & $21 \pm 5$ & 0 & 0 \\
\hline $7 \mathrm{c}$ & $\mathrm{F}$ & & $38 \pm 6$ & $43 \pm 5$ & $70 \pm 1$ & $52 \pm 1$ & $65 \pm 2$ & 0 \\
\hline
\end{tabular}


Table 1. Cont.

\begin{tabular}{|c|c|c|c|c|c|c|c|c|}
\hline \multirow{2}{*}{$\begin{array}{l}\text { Compound } \\
\text { Identity }\end{array}$} & \multicolumn{2}{|c|}{ Structure } & \multicolumn{3}{|c|}{ In Vitro Kinase Inhibition (\%) } & \multicolumn{3}{|c|}{ Cell Growth Inhibition (\%) } \\
\hline & R1 & $\mathbf{R} 2$ & FLT3 & $\begin{array}{c}\text { FLT3 } \\
\text { (D835Y) }\end{array}$ & $\begin{array}{l}\text { FLT3 } \\
\text { (ITD) }\end{array}$ & MV4-11 & Molm-13 & HL-60 \\
\hline $8 c$ & $\mathrm{~F}$ & & 0 & 0 & 0 & 0 & 0 & 0 \\
\hline $9 c$ & $\mathrm{~F}$ & & 0 & 0 & 0 & 0 & 0 & 0 \\
\hline $10 \mathrm{c}$ & & & $92 \pm 0$ & $94 \pm 2$ & $92 \pm 1$ & 0 & 0 & 0 \\
\hline 11c & & & $88 \pm 1$ & $91 \pm 3$ & $85 \pm 1$ & 0 & 0 & 0 \\
\hline
\end{tabular}

(a)<smiles>Fc1ccc(-c2cnc(Nc3ccccc3)o2)cc1</smiles>

(b)
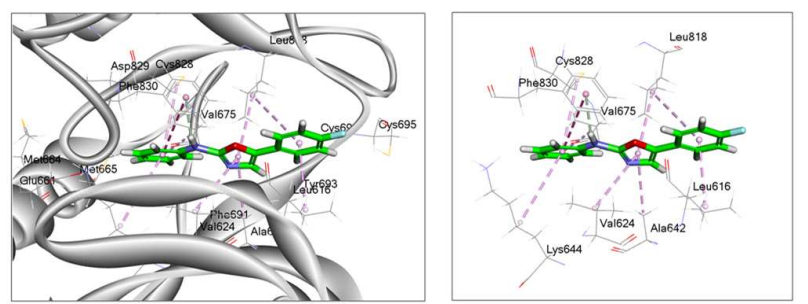

Figure 1. Structure of synthesized compound 7 (7c). (a) Chemical structure of 7c. (b) 3D binding mode and interaction of 7c with FMS-like tyrosine kinase 3 (FLT3). Green, 7c; pink dotted line, pi-alkyl bond. Relevant distances are expressed in $\AA$.

Table 2. Half maximal inhibitory concentration $\left(\mathrm{IC}_{50}\right)$ values of compound 7 (7c).

\begin{tabular}{|c|c|c|c|c|c|c|c|c|}
\hline \multirow{2}{*}{$\begin{array}{l}\text { Compound } \\
\text { Identity }\end{array}$} & \multicolumn{2}{|c|}{ Structure } & \multicolumn{3}{|c|}{$\mathrm{IC}_{50}(\mathrm{nM})(\mathrm{In}$ Vitro Kinase) } & \multicolumn{3}{|c|}{ IC $_{50}$ of Cell Growth (nM) } \\
\hline & R1 & $\mathbf{R} 2$ & FLT3 & $\begin{array}{c}\text { FLT3 } \\
\text { (D835Y) }\end{array}$ & $\begin{array}{l}\text { FLT3 } \\
\text { (ITD) }\end{array}$ & MV4-11 & Molm-13 & HL-60 \\
\hline $7 \mathrm{c}$ & $\mathrm{F}$ & & $207.2 \pm 3.4$ & $215.3 \pm 4.1$ & $32.5 \pm 2.5$ & $95.51 \pm 1.16$ & $61.9 \pm 2.45$ & $>10,000$ \\
\hline
\end{tabular}

To understand the interaction of 7c and FLT3, an in silico docking study was performed based on the crystal structure of FLT3 (PDB code: 4XUF) [15]. The aromatic ring of 7c showed a pi-alkyl interaction with $\mathrm{Val}^{675}$, $\mathrm{Lys}^{644}, \mathrm{Cys}^{828}$, $\mathrm{Leu}^{818}, \mathrm{Val}^{624}, \mathrm{Ala}^{642}$, and Leu ${ }^{616}$, as well as a pi-pi T-shaped interaction with $\mathrm{Phe}^{830}$ (Figure $1 \mathrm{~b}$ ). The results showed that $7 \mathrm{c}$ could inhibit the constitutive activation of FLT3 through direct binding, affecting AML cell growth. Consequently, 7c at $100 \mathrm{nM}$ concentration significantly inhibited $65.2 \%$ and $51.7 \%$ of Molm-13 and MV4-11 proliferation, respectively (Figure 2a and Table 1). We further investigated whether 7c treatment induced the apoptosis of Molm-13 and MV4-11 cells and observed that it increased the cleavage of caspase- 3 in both cell lines (Figure 2b). In vivo, 7c treatment significantly inhibited MV4-11-derived tumor growth by $83.3 \%$ compared with the control (Figure 2c). Besides, we measured the body weight of mice to determine 7c toxicity and did not observe any significant differences between the 7c-treated and control groups (Figure 2d). Overall, 7c exhibited anti-leukemic activity both in vitro and in vivo. 
(a)

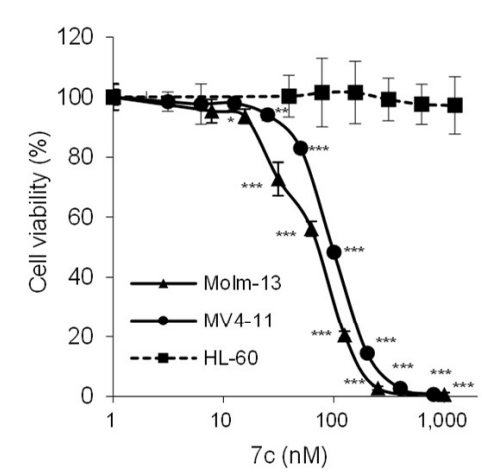

(c)

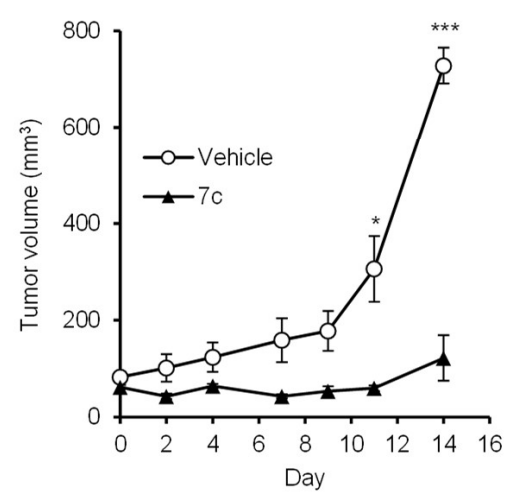

(b)

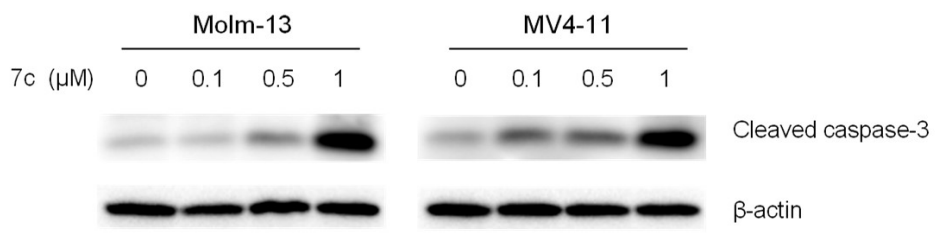

(d)

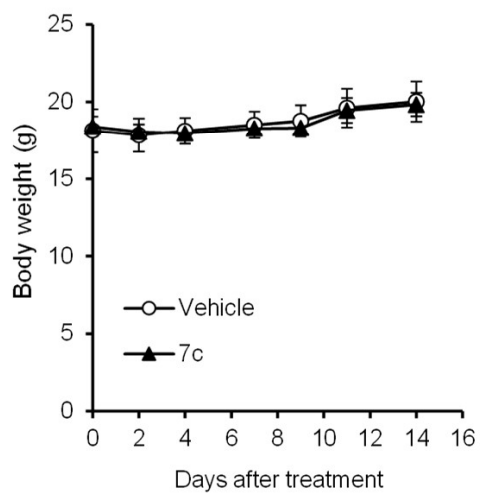

Figure 2. Compound 7c inhibited FMS-like tyrosine kinase 3-internal tandem duplication-positive acute myeloid leukemia (FLT3-ITD ${ }^{+}$AML) cells. (a) Human FLT3-ITD ${ }^{+}$AML cells (Molm-13 and MV4-11) and FLT3-null AML cells (HL-60) were treated with 7c at the indicated concentrations for 5 days and viable cells were evaluated using the CCK-8 assay. (b) Cell lysates were prepared at $48 \mathrm{~h}$ after treatment with $7 \mathrm{c}$ and determined by immunoblotting for cleaved caspase- 3 . $\beta$-actin was used as the loading control. (c) MV4-11 cells mixed with Matrigel were subcutaneously injected into the right hind leg thigh of BALB/c nu/nu mice ( $n=5 /$ vehicle control group, $n=5$; treatment group, $n=10$ ). Tumor size was measured on the indicated day after the first $7 \mathrm{c}$ intraperitoneal administration. Tumor volume $\left(\mathrm{mm}^{3}\right)$ was calculated as follows: (longest axis $\times$ shortest axis of tumor) ${ }^{2} / 2$. (d) Body weight of MV4-11 tumor xenograft mice was determined twice weekly during the experiments. Significant difference was defined as ${ }^{*}$ at $p<0.05,{ }^{* *}$ at $p<0.01$, and ${ }^{* *}$ at $p<0.001$.

\subsection{7c Inhibited the FLT3 Kinase Activity in AML Cells}

FLT3-ITD activates FLT3 in the absence of FLT3 ligands and causes aberrant activation of STAT5 with phosphorylation in downstream signaling, leading to rapid cell proliferation and malignancy. We investigated whether 7c inhibited FLT3 signaling in FLT3-ITD ${ }^{+}$Molm-13 and MV4-11 cells in vitro. Consistent with the results of the in vitro kinase assay, phosphorylated FLT3 was inhibited by 7c treatment in a concentration-dependent manner in both cell lines. Besides, we also observed that 7c inhibited FLT3-downstream effector STAT5 phosphorylation and total STAT5 protein in Molm-13 and MV4-11 cells (Figure 3). However, 7c did not regulate the phosphorylation of STAT5 in HL-60 cells (Figure S3). Thus, 7c could be used as an FLT3 inhibitor using a cell-free kinase assay and a cell-based assay. 


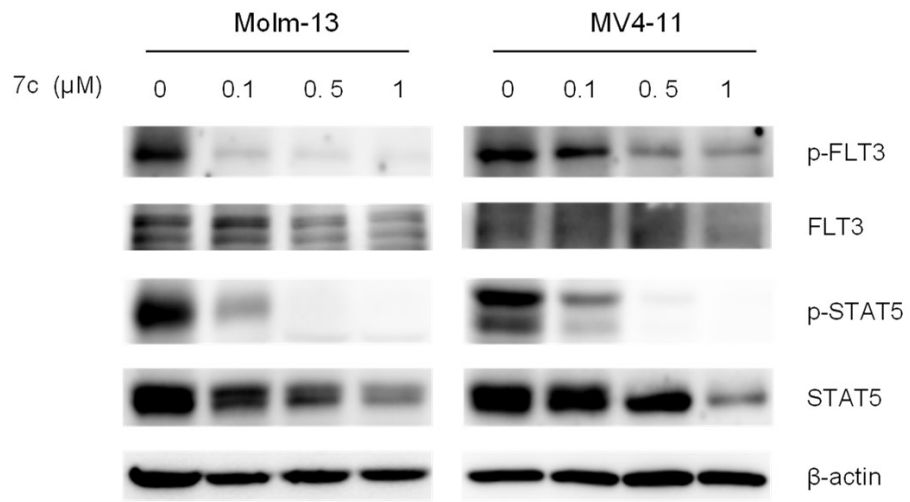

Figure 3. Compound 7c inhibited FMS-like tyrosine kinase 3 (FLT3) signaling. Human FLT3-internal tandem duplication-positive acute myeloid leukemia (FLT3-ITD ${ }^{+}$AML) cells (Molm-13 and MV4-11) were treated with $7 \mathrm{c}$ at the indicated concentrations for $48 \mathrm{~h}$, and cell lysates were subjected to immunoblotting for detecting FLT3 and STAT5. $\beta$-actin was used as the loading control.

\subsection{7c Suppressed DNA Damage Repair}

Previous studies suggested that FLT3-ITD increases the ROS levels in AML cells, inducing DNA damage, mutations, and chromosomal instability $[9,10]$. Inhibition of FLT3-ITD function by quizartinib reduces two major DSB repair activities with homologous recombination (HR) and non-homologous end-joining (NHEJ). Our previous study supported that quizartinib and the novel FLT3 inhibitor AIU2001 downregulate DNA repair HR and NHEJ genes [10,11]. To investigate whether $7 \mathrm{c}$-induced AML cell death was caused by the inhibition of DNA damage repair pathways, we determined the expression levels of HR and NHEJ genes in Molm-13 and MV4-11 cells. The results showed that 7c significantly downregulated the mRNA and protein levels of HR (BRCA1, BRCA2, BARD1, and RAD51) and NHEJ (XRCC4, XRCC5, and XRCC6) genes in both cell lines (Figure 4a,b). Since DNA repair genes and proteins are downregulated, DNA damage was determined by detection of phosphorylation on Ser139 of H2AX ( $\gamma-\mathrm{H} 2 \mathrm{AX})$, which is an indicator of presence of DNA double strand damage, in Molm-13 and MV4-11 cells. We observed that 7c induced $\gamma-\mathrm{H} 2 \mathrm{AX}$ in both cells (Figure S3). These results indicated that $7 \mathrm{c}$ downregulated the DNA damage repair genes and induced DNA damage, probably contributing to anti-leukemic activities and leading to AML cell death.

\subsection{Combination Therapy of $7 c$ with a PARP Inhibitor Showed Synthetic Lethality}

We investigated whether $7 \mathrm{c}$ could sensitize FLT3-ITD ${ }^{+}$AML cells to olaparib (PARP inhibitor) in combination therapy. Olaparib is the first PARP inhibitor targeting mainly PARP 1 and 2 approved by the FDA to treat advanced ovarian cancer patients with germline BRCA mutations and is widely studied in combination with DNA damage-induced drugs or radiotherapy. Our results showed that 7c and olaparib exerted synergistic growth inhibition in Molm-13 and MV4-11 cells (Figure 5) and that 7c could sensitize FLT3-ITD ${ }^{+}$AML cells to PARP inhibition. Therefore, combination treatment with $7 \mathrm{c}$ and a PARP inhibitor might increase the effectiveness of AML therapy. We observed synergistic growth inhibition at a wide range of concentrations of $7 c$ and olaparib in both cell lines (Figure $5 b$ ), indicating that $7 \mathrm{c}$ could sensitize FLT3-ITD ${ }^{+}$AML cells to PARP inhibition. Therefore, combination treatment with $7 \mathrm{c}$ and a PARP inhibitor would be more effective for anti-leukemic therapy. 
(a)
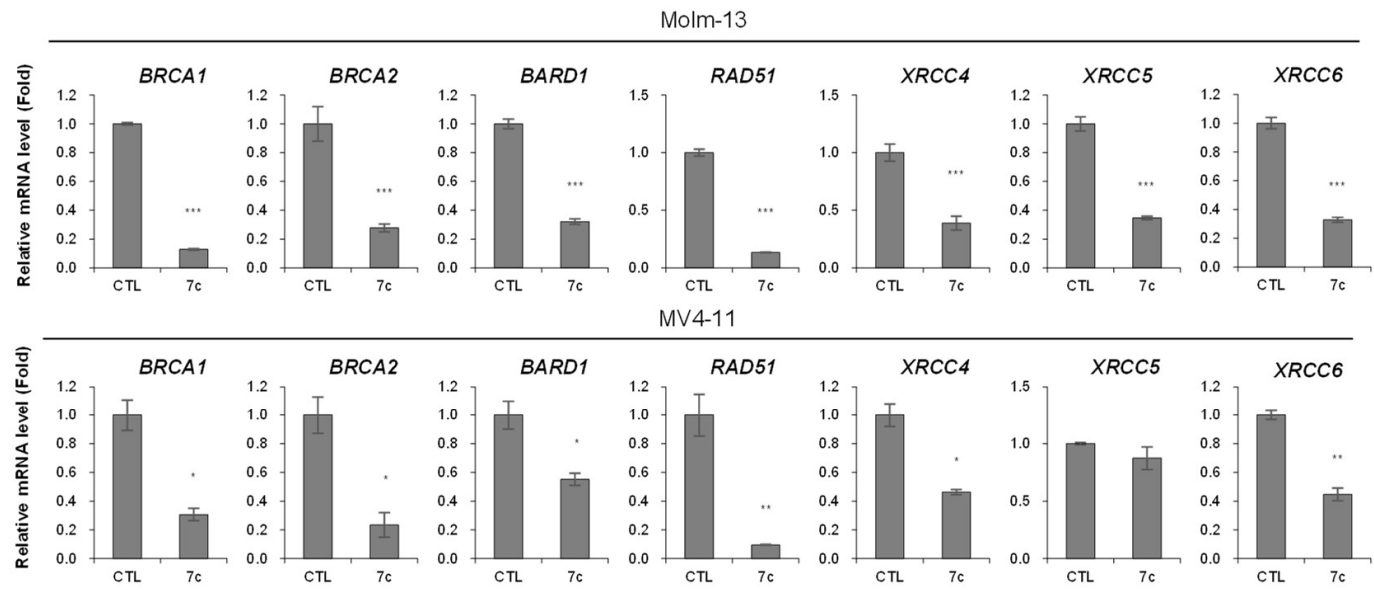

(b)

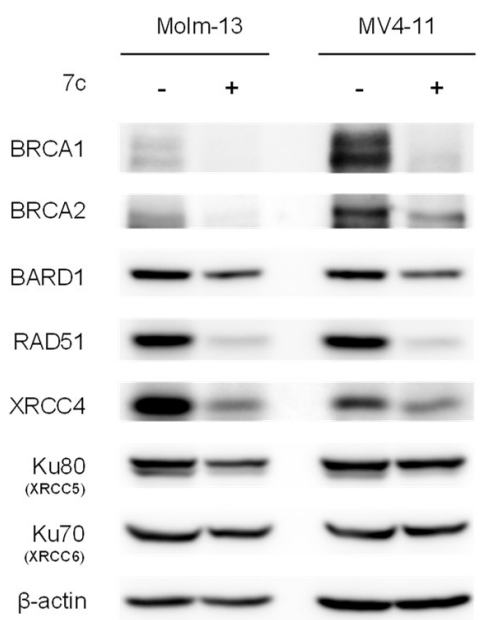

Figure 4. Compound 7c inhibited DNA damage repair. (a) Human FMS-like tyrosine kinase 3-internal tandem duplication-positive acute myeloid leukemia (FLT3-ITD ${ }^{+}$AML) cells (Molm-13 and MV4-11) were treated with $1 \mu \mathrm{M} 7 \mathrm{c}$ for $18 \mathrm{~h}$ to quantify the mRNA expression of the indicated genes by qRT-PCR. Data are from one representative experiment that repeated in triplicate. (b) Cell lysates were prepared $24 \mathrm{~h}$ after treatment with 7c and subjected to immunoblotting for detecting the indicated proteins. Data are from one representative experiment that has three replicates. Significant difference was defined as ${ }^{*}$ at $p<0.05,^{* *}$ at $p<0.01$, and ${ }^{* * *}$ at $p<0.001$. 
(a)

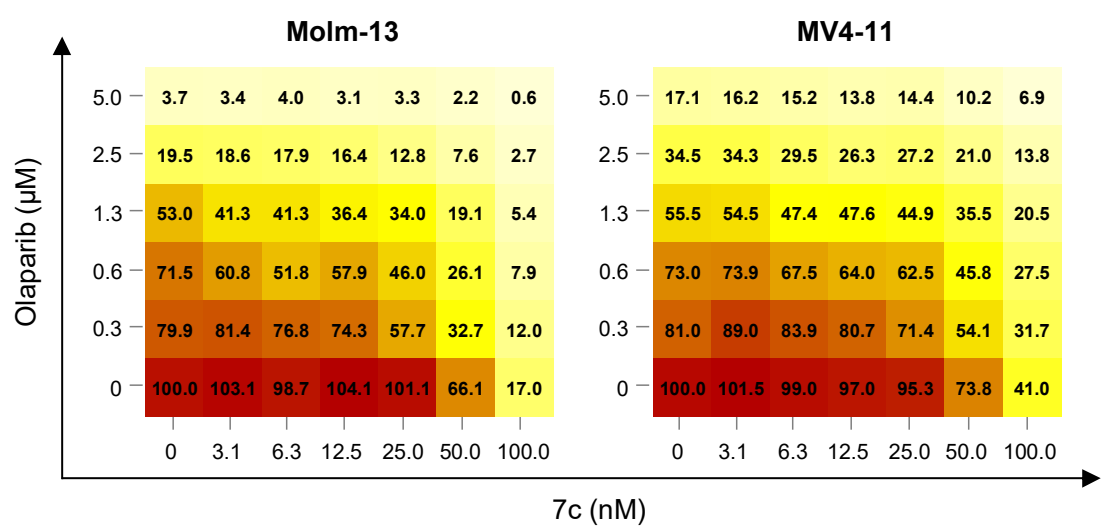

(b)

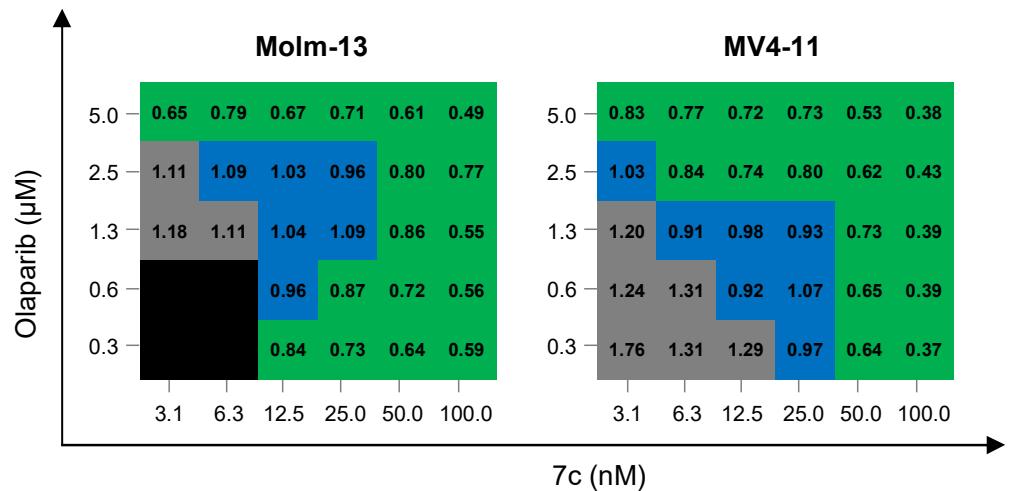

Figure 5. Combination treatment with compound 7c and olaparib synergistically inhibited cell growth. (a) Human FMS-like tyrosine kinase 3-internal tandem duplication-positive acute myeloid leukemia (FLT3-ITD ${ }^{+}$AML) cells (Molm-13 and MV4-11) were treated with 7c or olaparib or both at the indicated concentrations. Cell viability was determined using the CCK-8 assay 5 days post treatment. Relative viability is shown for each combination at the indicated concentrations. Data are from one representative experiment that had four replicates. (b) Combination index (CI) scores of $7 \mathrm{c}$ and olaparib combination at the indicated concentrations in Molm-13 and MV4-11 cells. Green, synergistic $(\mathrm{CI}<0.9)$; blue, additive ( $1.1 \geq C I \geq 0.9)$; gray, antagonistic ( $C I>1.1)$; black, non-significant. Each CI score represents average data derived from the indicated concentrations of single and combined compound treatments in four independent experiments.

\section{Discussion}

In the present study, we identified novel kinase inhibitors targeting FLT3 using the in vitro kinase and cell viability assays in AML cell lines. Of the 11 synthesized compounds, $7 \mathrm{c}$ was found to be a potent FLT3 inhibitor with anti-leukemic effects in vitro and in vivo. Although 5c, 10c, and 11c showed excellent inhibitory efficacy at $100 \mathrm{nM}$ concentration against FLT3, FLT3-D835Y, and FLT3-ITD in vitro, significant growth inhibition was not observed in FLT-ITD-positive Molm-13 and MV4-11 cell lines. To identify contradictory efficacy results between cell-free and cell-based assays, we conducted an in silico physicochemical character analysis. The results showed that the $\mathrm{pKa}$ value of $7 \mathrm{c}$ is similar to that of quizartinib, which was used as the reference, whereas that of $5 \mathbf{c}, \mathbf{1 0 c}$, and $\mathbf{1 1} \mathbf{c}$ was relatively low (Table S1), probably owing to differences in chemical characteristics such as intracellular drug dissolution, absorption, and stability [16]. Overall, $7 \mathrm{c}$ is a promising therapeutic agent; however, further research is required to more thoroughly investigate its structure, activity relationship, metabolism, pharmacokinetics, and off-target profiling.

Previous studies revealed a relationship between FLT3-ITD signaling and DNA damage. The phosphorylation of STAT5 increases ROS generation through direct association with the GTP-binding protein RAC1 in FLT3-ITD ${ }^{+}$AML cells [9]. Increased ROS levels trigger DNA oxidation, 
genomic instability, DNA DSB, and error-prone DNA damage repair, whereas the enhanced DNA repair activities allow mutagenesis and malignancy, leading to the acquisition of genomic changes and aggressive AML [17,18]. Genomic instability is a pathologic feature of FLT3-ITD ${ }^{+}$AML [19]; therefore, inhibition of DNA damage repair can induce the death of FLT3-ITD ${ }^{+}$AML cells. Here, we showed that 7c inhibited FLT3-STAT5 signaling as well as HR and NHEJ DNA repair genes, probably contributing to the growth inhibition and death of FLT3-ITD ${ }^{+}$AML cells. These results are consistent with those of our previous study, in which we demonstrated that the inhibition of STAT5 downregulates DNA repair [11]. Previous studies suggested that AML with genomic instability is sensitive to PARP inhibition $[10,20]$. Our results showed that the combination of $7 \mathrm{c}$ and olaparib synergistically inhibited FLT3-ITD ${ }^{+}$AML cells, revealing that an FLT3 inhibitor and a PARP inhibitor could be a promising therapeutic approach for FLT3-ITD ${ }^{+}$AML.

All novel putative drugs must be validated for efficacy and off-target toxicity. The multiple class III RTK inhibitor midostaurin was approved by the FDA in 2017 for the treatment of FLT3-mutant AML, whereas the FDA rejected the selective FLT3 inhibitor quizartinib in 2019. Thus, there is a need to develop novel inhibitors targeting FLT3.

In summary, we identified a novel FLT3 inhibitor, 7c, as an anti-AML agent that inhibited FLT3 signaling in both in vitro kinase and cell-based assays. Treatment with $7 \mathrm{c}$ downregulated HR and NHEJ repair genes, leading to the inhibition of growth and induction of apoptosis in FLT3-ITD ${ }^{+}$AML cells. Besides, the combination of $7 \mathrm{c}$ and olaparib significantly inhibited cell proliferation. Overall, our findings suggest that $7 \mathrm{c}$ could be a potential anti-leukemic agent.

\section{Materials and Methods}

\subsection{Chemistry}

All chemical reagents were commercially available and used without further purification. Melting points were determined using the M5000 Melting Point apparatus (Kruss, Hamburg, Germany) and used without any correction. Proton nuclear magnetic resonance (NMR) spectra were recorded using the Avance-500 spectrometer (Bruker, Billerica, MA, USA) at $500 \mathrm{MHz}$. Chemical shifts are reported in ppm, and Me4Si was used as the reference standard. Mass spectra were recorded using JMS-600W VG Trio-2 GC-MS (Jeol, Akishima, Japan). Reaction products were purified by flash column chromatography using silica gel 60 (230-400 mesh) and monitored by thin-layer chromatography with precoated silica gel 60 F254 (Merck, Darmstadt, Germany). Spots were visualized under UV light (254 nm) after staining with PMA or Hanessian solution.

5-(4-Fluorophenyl)-N-phenyloxazol-2-amine (7c). Pale yellow solid, $\mathrm{mp}=160-162{ }^{\circ} \mathrm{C},{ }^{1} \mathrm{H}$ NMR $\left(300 \mathrm{MHz}, \mathrm{DMSO}_{-} \mathrm{d}_{6}\right) \delta 10.31(\mathrm{~s}, 1 \mathrm{H}), 7.57-7.68(\mathrm{~m}, 5 \mathrm{H}), 7.26-7.35(\mathrm{~m}, 4 \mathrm{H}), 6.89-7.03(\mathrm{~m}, 1 \mathrm{H})$; MS (FAB) $m / z 254\left(\mathrm{M}^{+}\right)$.

\subsection{General Synthesis Procedure}

Azide was produced as previously described [21]. Briefly, phenacyl bromide (1.0 eq) was added dropwise to a solution of sodium azide (3.0 eq) in a 3:1 mixture of acetone and water. The resulting mixture was stirred at room temperature for $16 \mathrm{~h}$. The reaction mixture was diluted with water and extracted with ethyl acetate. The combined organic layer was washed with brine, dried over sodium sulfate, and concentrated in vacuo to generate the product (93\% yield). Isothiocyanate was produced as previously described [22]. Briefly, thiophosgene (1.2 eq) was slowly added to a cold solution $\left(0^{\circ} \mathrm{C}\right)$ of amine $(1.0 \mathrm{eq})$ in dichloromethane $(0.3 \mathrm{M})$ and stirred at $0{ }^{\circ} \mathrm{C}$ for $20 \mathrm{~min}$. The resulting mixture was stirred at room temperature for $4 \mathrm{~h}$, diluted with a saturated solution of $\mathrm{K}_{2} \mathrm{CO}_{3}$, and extracted with DCM several times. The combined organic layers were dried over anhydrous sodium sulfate, filtered, and concentrated in vacuo to generate the product ( $86 \%$ yield). Isooxazole was produced as previously described [23]. Briefly, $\mathrm{PPh}_{3}(1.0 \mathrm{eq})$ was added to a solution of azide (1.0 eq) and isothiocyanate (1.0 eq) in dioxane $(0.2 \mathrm{M})$. The resulting mixture was heated to $90^{\circ} \mathrm{C}$ and stirred for $4 \mathrm{~h}$. The solvent was 
cooled at room temperature and evaporated under reduced pressure. The residue was purified by flash column chromatography over silica gel with EtOAc/hexane (1:10) to generate the product (32\% yield).

\subsection{Cell Culture}

Human AML cell lines, Molm-13, MV4-11, and HL-60 were maintained in Roswell Park Memorial Institute (RPMI)- 1640 (Molm-13; Welgene, Gyeongsan, Korea) and Iscove's Modified Dulbecco's Medium (IMDM) (MV4-11, HL-60; Gibco, Waltham, MA, USA) media supplemented with $10 \%$ fetal bovine serum (Welgene) and 1\% penicillin-streptomycin (Gibco). Culture flasks were incubated at $37^{\circ} \mathrm{C}, 5 \% \mathrm{CO}_{2}$, and $95 \%$ relative humidity.

\subsection{Tumor Xenograft Mouse Model}

MV4-11 cells were resuspended in 10\% Matrigel for tumor solidification and subcutaneously (s.c.) implanted into the right hind leg thigh of 6-week-old BALB/c nu/nu mice. When the tumor volume reached approximately $80 \mathrm{~mm}^{3}$, compound $7\left(7 \mathrm{c} ; 10 \mathrm{mg} \mathrm{kg}^{-1}\right)$ was administered intraperitoneally (i.p.) once every 2 day for three times. Tumor size was measured twice a week using vernier calipers and tumor volume calculated as follows:

Tumor volume $=(\text { longest tumor axis } \times \text { shortest tumor axis })^{2} / 2 \mathrm{~mm}^{3}$.

All animal experiments were conducted in accordance with institutional guidelines and were approved by the Institutional Animal Care Use Committee (IACUC; KIRAMS-BT15-029).

\subsection{Cell ViabIlity Assay}

Cell viability was determined using the Cell Counting Kit-8 (CCK-8) (Dojindo, Japan). Molm-13, MV4-11, and HL-60 were seeded in 96-well plates at a density of $8 \times 10^{2}, 2 \times 10^{3}$, and $1.2 \times 10^{3}$ cells per well, respectively. Experimental groups were treated with $7 \mathrm{c}$ and incubated at $37^{\circ} \mathrm{C}$ and $95 \%$ relative humidity for $5 \mathrm{~d}$, whereas the control groups were treated with dimethyl sulfoxide (DMSO) and incubated under the same conditions. CCK-8 solution was added to each well with cells and the absorbance of the sample was measured at $450 \mathrm{~nm}$ using a 96-well plate reader (Multiskan EX; Thermo Lab Systems, Waltham, MA, USA).

\subsection{Western Blotting}

Proteins were extracted from cell lysates using TNN (40 mM Tris- $\mathrm{HCl}$ (pH 8.0), 0.2\% NP-40, $120 \mathrm{mM} \mathrm{NaCl}$ ) buffer or RIPA lysis buffer (Millipore, Burlington, MA, USA) supplemented with protease inhibitor (Thermo Fisher Scientific, Waltham, MA, USA). Proteins samples, loaded at equal amounts, were separated by sodium dodecyl sulfate polyacrylamide gel electrophoresis on 6-15\% gels, and then transferred on to nitrocellulose membranes (Bio-Rad, Hercules, CA USA). The membranes were washed and blocked with 5\% skim milk in TBS-T ( $150 \mathrm{mM} \mathrm{NaCl}, 10 \mathrm{mM}$ Tris, $0.2 \%$ Tween 20), and then incubated overnight with primary antibodies at $4{ }^{\circ} \mathrm{C}$. Secondary antibodies conjugated to peroxidase and visualized immunoreactive proteins enhanced by ECL reagent were detected using ImageQuan LAS 4000 mini (GE Healthcare, Amersham, UK).

\subsection{Quantitative Real-Time Polymerase Chain Reaction ( $q R T-P C R$ )}

The total RNA was extracted from the cell lysate using TRIzol ${ }^{\circledR}$ (Thermo Fisher Scientific, USA) to synthesize cDNA using CycleScript reverse transcriptase (Bioneer, Daejeon, Korea). cDNA was mixed with target sequence primers and Maxima SYBR Green/Fluorescein qPCR Master Mix (Thermo Scientific, USA). The sequence of the designed primers targeting DNA repair genes is as follows: BRCA1, forward 5'-CTGAAGACTGCTCAGGGCTATC-3' , reverse 5'-AGGGTAGCTGTTAGAAGGCTGG-3'; BRCA2, forward $5^{\prime}$-GGCTTCAAAAAGCACTCCAGATG-3' ${ }^{\prime}$, reverse $5^{\prime}$-GGATTCTGTATCTCTT GACGTTCC-3'; RAD51, forward 5'-CTCAGCCTCCCGAGTAGTTG-3', reverse 5'-CATCACTGC CAGAGAGACCA-3' ; BARD1, forward 5' -GCCAAAGCTGTTTGATGGAT-3' , reverse 5' -CGAACCCT 
CTCTGGGTGATA-3'; XRCC4, forward 5' - CATTGTT GTCAGGAGCAGGA-3' , reverse 5' -TCTGCAG GTGCTCATTTTTG-3'; XRCC5, forward 5'-CGACA GGTGTTTGCTGAGAA-3' , reverse 5'-TCA CATCCATGCTCACGATT-3'; XRCC6, forward 5'-AAAAGACTGGGCTCCTTGGT-3' , reverse 5'-TGT GGGTCTTCAGCTCCTCT-3'. 18S ribosomal RNA was used as a housekeeping gene to normalize samples. The housekeeping gene sequence is as follows: forward 5' -CACGCCAGTACAAGATCCCA-3' reverse 5'-TTCACGGAGCTTGTCCA-3'. The conditions of qRT-PCR were as follows: initial duration at $95{ }^{\circ} \mathrm{C}$ for $10 \mathrm{~min}$, followed by 50 cycles at $95^{\circ} \mathrm{C}$ for $15 \mathrm{~s}, 60^{\circ} \mathrm{C}$ for $30 \mathrm{~s}$, and $72{ }^{\circ} \mathrm{C}$ for $30 \mathrm{~s}$. The PCR products were detected and analyzed using the LightCycler 96 system (Roche, Basel, Switzerland). The mRNA level was indicated as the fold change relative to the control. Experiments were carried out in triplicate.

\subsection{In Vitro Kinase Assay}

In vitro kinase profiling of the 11 synthesized compounds was performed by Reaction Biology Corporation (Malvern Panalytical, Malvern, UK).

\subsection{Molecular Docking Study}

Ligand preparation and optimization were conducted using the Prepare Ligands module of Discovery Studio 2019 (Biovia, San Diego, CA, USA). The FLT3 protein structure, as described previously [15], was downloaded from the RCSB-PDB database (http://www.rcsb.org). Before docking, the original crystal ligand quizartinib (AC220) and water molecules were removed from the protein-ligand complexes. Hydrogen atoms were added using the CHARMm force field and the Momany-Rone partial charge as default settings in Discovery Studio 2019. The ligand-binding site was extracted from RCSB-PDB and designated as active site 1. Docking analysis of compounds with the FLT3 protein in the presence of quizartinib was performed using the CDOCKER module. The number of generated poses was set at 100 for each ligand, whereas default settings were selected for other parameters.

\subsection{Combination Index (CI)}

CI scores were calculated using CompuSyn (ComboSyn, Paramus, NJ, USA) after single- and paired-compound treatment. The CI of the two compounds was calculated as follows:

$$
C I=\frac{(D) A}{(D x) A}+\frac{(D) B}{(D x) B}
$$

\subsection{Statistical Analysis}

Data are presented as mean \pm standard deviation or standard error. Analysis of variance in conjunction with Student's $t$-test was carried out to identify significant differences at $p<0.05$.

Supplementary Materials: The following are available, Figure S1: Compounds 2c, 3c, 4c, 5c, 6c, 10c, and 11c slightly inhibited growth of AML cell lines; Table S1: In silico physicochemical properties of four synthesized compounds compared with quizartinib.

Author Contributions: Study design: J.A.; study conception: J.A., J.-Y.S., S.-G.H.; chemical design and synthesis: H.-K.C. and S.S.J.; all biological experiments and data analysis: H.J.K. and H.R.; manuscript writing: J.A., H.J.K., and H.-K.C. All authors have read and agreed to the published version of the manuscript.

Funding: This study was supported by the National Research Foundation of Korea (NRF; 2019R1A2C1009238) and the Korea Institute of Radiological and Medical Sciences (50531-2020; 50538-2020) funded by the Korean government Ministry of Science and ICT.

Conflicts of Interest: The authors declare no conflict of interest. The funders had no role in the design of the study; in the collection, analyses, or interpretation of data; in the writing of the manuscript, or in the decision to publish the results. 


\section{References}

1. De Kouchkovsky, I.; Abdul-Hay, M. Acute myeloid leukemia: A comprehensive review and 2016 update. Blood Cancer J. 2016, 6, e441. [CrossRef] [PubMed]

2. Döhner, H.; Estey, E.H.; Amadori, S.; Appelbaum, F.R.; Büchner, T.; Burnett, A.K.; Dombret, H.; Fenaux, P.; Grimwade, D.; Larson, R.A.; et al. Diagnosis and management of acute myeloid leukemia in adults: Recommendations from an international expert panel, on behalf of the European LeukemiaNet. Blood 2010, 115, 453-474. [CrossRef] [PubMed]

3. Yang, X.; Wang, J. Precision therapy for acute myeloid leukemia. J. Hematol. Oncol. 2018, 11, 1-11. [CrossRef] [PubMed]

4. Zhou, F.; Ge, Z.; Chen, B. Quizartinib (AC220): A promising option for acute myeloid leukemia. Drug Des. Dev. Ther. 2019, 13, 1117-1125. [CrossRef] [PubMed]

5. Döhner, H.; Weisdorf, D.J.; Bloomfield, C.D. Acute Myeloid Leukemia. New Engl. J. Med. 2015, 373, $1136-1152$. [CrossRef] [PubMed]

6. Small, D. FLT3 Mutations: Biology and Treatment. Hematology 2006, 2006, 178-184. [CrossRef] [PubMed]

7. Daver, N.; Schlenk, R.F.; Russell, N.H.; Levis, M.J. Targeting FLT3 mutations in AML: Review of current knowledge and evidence. Leukemia 2019, 33, 299-312. [CrossRef]

8. Larrosa-Garcia, M.; Baer, M.R. FLT3 Inhibitors in Acute Myeloid Leukemia: Current Status and Future Directions. Mol. Cancer Ther. 2017, 16, 991-1001. [CrossRef] [PubMed]

9. Sallmyr, A.; Fan, J.; Datta, K.; Kim, K.T.; Grosu, D.; Shapiro, P.; Small, D.; Rassool, F. Internal tandem duplication of FLT3 (FLT3/ITD) induces increased ROS production, DNA damage, and misrepair: Implications for poor prognosis in AML. Blood 2008, 111, 3173-3182. [CrossRef] [PubMed]

10. Maifrede, S.; Nieborowska-Skorska, M.; Sullivan-Reed, K.; Dasgupta, Y.; Podszywalow-Bartnicka, P.; Le, B.V.; Solecka, M.; Lian, Z.; Belyaeva, E.A.; Nersesyan, A.; et al. Tyrosine kinase inhibitor-induced defects in DNA repair sensitize FLT3(ITD)-positive leukemia cells to PARP1 inhibitors. Blood 2018, 132, 67-77. [CrossRef]

11. Ryu, H.; Choi, H.K.; Kim, H.J.; Kim, A.-Y.; Song, J.-Y.; Hwang, S.-G.; Kim, J.-S.; Kim, D.-U.; Kim, E.-H.; Kim, J.; et al. Antitumor Activity of a Novel Tyrosine Kinase Inhibitor AIU2001 Due to Abrogation of the DNA Damage Repair in Non-Small Cell Lung Cancer Cells. Int. J. Mol. Sci. 2019, 20, 4728. [CrossRef]

12. Bulatov, E.; Sayarova, R.; Mingaleeva, R.; Miftakhova, R.; Gomzikova, M.; Ignatyev, Y.; Petukhov, A.; Davidovich, P.; Rizvanov, A.; Barlev, N.A. Isatin-Schiff base-copper (II) complex induces cell death in p53-positive tumors. Cell Death Discov. 2018, 4, 1-9. [CrossRef]

13. Hassa, P.O.; Hottiger, M.O. The diverse biological roles of mammalian PARPS, a small but powerful family of poly-ADP-ribose polymerases. Front. Biosci. 2008, 13, 3046-3082. [CrossRef]

14. Haince, J.-F.; McDonald, D.; Rodrigue, A.; Déry, U.; Masson, J.-Y.; Hendzel, M.J.; Poirier, G.G. PARP1-dependent Kinetics of Recruitment of MRE11 and NBS1 Proteins to Multiple DNA Damage Sites. J. Biol. Chem. 2007, 283, 1197-1208. [CrossRef]

15. Zorn, J.A.; Wang, Q.; Fujimura, E.; Barros, T.; Kuriyan, J. Crystal Structure of the FLT3 Kinase Domain Bound to the Inhibitor Quizartinib (AC220). PLoS ONE 2015, 10, e0121177. [CrossRef]

16. Chan, A.; Orme, R.P.; Fricker, R.A.; Roach, P. Remote and local control of stimuli responsive materials for therapeutic applications. Adv. Drug Deliv. Rev. 2013, 65, 497-514. [CrossRef]

17. Sallmyr, A.; Fan, J.; Rassool, F.V. Genomic instability in myeloid malignancies: Increased reactive oxygen species (ROS), DNA double strand breaks (DSBs) and error-prone repair. Cancer Lett. 2008, 270, 1-9. [CrossRef]

18. Mi, T.; Wang, Z.; Bunting, K.D. The Cooperative Relationship between STAT5 and Reactive Oxygen Species in Leukemia: Mechanism and Therapeutic Potential. Cancers 2018, 10, 359. [CrossRef]

19. Rebechi, M.T.; Pratz, K.W. Genomic instability is a principle pathologic feature of FLT3 ITD kinase activity in acute myeloid leukemia leading to clonal evolution and disease progression. Leuk. Lymphoma 2017, 58, 2040-2050. [CrossRef]

20. Dellomo, A.J.; Baer, M.R.; Rassool, F.V. Partnering with PARP inhibitors in acute myeloid leukemia with FLT3-ITD. Cancer Lett. 2019, 454, 171-178. [CrossRef]

21. Yang, X.; Wedajo, W.; Yamada, Y.; Dahlroth, S.-L.; Neo, J.J.-L.; Dick, T.; Chui, W.-K. 1,3,5-triazaspiro[5.5] undeca-2,4-dienes as selective Mycobacterium tuberculosis dihydrofolate reductase inhibitors with potent whole cell activity. Eur. J. Med. Chem. 2018, 144, 262-276. [CrossRef] 
22. Kai, H.; Morioka, Y.; Tomida, M.; Takahashi, T.; Hattori, M.; Hanasaki, K.; Koike, K.; Chiba, H.; Shinohara, S.; Kanemasa, T.; et al. 2-Arylimino-5,6-dihydro-4H-1,3-thiazines as a new class of cannabinoid receptor agonists. Part 2: Orally bioavailable compounds. Bioorganic Med. Chem. Lett. 2007, 17, 3925-3929. [CrossRef] [PubMed]

23. Suh, J.H.; Yum, E.K.; Cho, Y.S. Synthesis and Biological Evaluation of N-Aryl-5-aryloxazol-2-amine Derivatives as 5-Lipoxygenase Inhibitors. Chem. Pharm. Bull. 2015, 63, 573-578. [CrossRef] [PubMed]

Sample Availability: Samples of the compounds are not available from the authors.

Publisher's Note: MDPI stays neutral with regard to jurisdictional claims in published maps and institutional affiliations.

(C) 2020 by the authors. Licensee MDPI, Basel, Switzerland. This article is an open access article distributed under the terms and conditions of the Creative Commons Attribution (CC BY) license (http://creativecommons.org/licenses/by/4.0/). 